\title{
O ESTÁGIO E A FORMAÇÃO EM GESTÃO EDUCACIONAL NO CURSO DE PEDAGOGIA DA UNIVERSIDADE ESTADUAL DE PONTA GROSSA (PR)
}

\author{
INTERNSHIP AND EDUCATION MANAGEMENT QUALIFICATION IN THE EDUCATION \\ COURSE AT THE STATE UNIVERSITY OF \\ PONTA GROSSA
}

$(P R)$

\section{LA PASANTÍA Y LA FORMACIÓN EN GESTIÓN EDUCACIONAL EN EL CURSO DE PEDAGOGÍA DE LA UNIVERSIDAD ESTADUAL DE PONTA GROSSA}

(PR)

\author{
Beatriz Gomes Nadal \\ Universidade Estadual de Ponta Grossa \\ E-mail: beatrizgnadal@gmail.com \\ Elismara Zaias Kailer \\ Universidade Estadual de Ponta Grossa \\ E-mail: elismarazaias@yahoo.com.br \\ Patrícia Correia de Paula Marcoccia \\ E-mail: pa.tyleo12@gmail.com
}

\begin{abstract}
RESUMO
O presente trabalho tematiza o estágio na formação em gestão educacional no Curso de Pedagogia da Universidade Estadual de Ponta Grossa. Considera que a formação para atuação neste campo foi historicamente assumida pelo curso, o que pressupõe uma formação profissional capaz de responder aos conhecimentos específicos deste campo, assim como de desenvolver tal identidade ao longo da formação. Reconhece o estágio como dimensão essencial nesse processo pelas possibilidades de produção de sínteses teórico-práticas que sua dinâmica viabiliza. O objetivo do artigo é discutir o papel do estágio na formação das equipes de gestão no âmbito do Curso de Pedagogia da UEPG, problematizando o modo pelo qual situações didáticas podem mediar as relações teórico-práticas, o estabelecimento de sínteses, o desenvolvimento de aprendizagens e formação profissional no campo da gestão escolar.
\end{abstract}

PALAVRAS-CHAVE: Formação de Professores. Curso de Pedagogia. Gestão educacional e escolar. Estágio. Práxis.

\section{ABSTRACT}

This study approaches internship within the education management qualification in the education course at the State University of Ponta Grossa. It considers that the qualification to act in this area has been historically undertaken by the course, which implies professional qualification that is able to respond to the specific knowledge in this area, as well as to develop such identity throughout the course. It recognizes internship as an essential dimension in this process due to the possibilities created to produce theoretical-practical syntheses made possible by its dynamics. The objective of this paper is to discuss the role of internship in the qualification of management teams in the education course at UEPG, questioning the way certain teaching situations might mediate theoretical-practical relations, the establishment of syntheses, learning development and professional qualification in the school management area. 


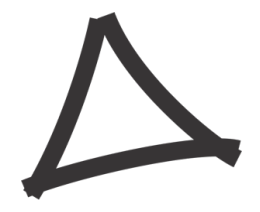

\section{Revista Triângulo}

KEYWORDS: Teachers' initial education. Education Course. Education and School Management Internship. Praxis.

\section{RESUMEN}

El presente trabajo tematiza la pasantía en la formación en gestión educacional en el Curso de Pedagogía de la Universidad Estadual de Ponta Grossa. Considera que la formación para actuación en este campo fue históricamente asumida por el curso, lo que presupone una formación profesional capaz de responder a los conocimientos específicos de este campo, así como de desarrollar tal identidad a lo largo de la formación. Reconoce la pasantía como dimensión esencial en ese proceso por las posibilidades de producción de síntesis teórico-prácticas que su dinámica viabiliza. El objetivo del artículo es discutir el papel de la pasantía en la formación de los equipos de gestión en el ámbito del Curso de Pedagogía de la UEPG, problematizando el modo por el cual situaciones didácticas pueden mediar las relaciones teórico-prácticas, el establecimiento de sintesis, el desarrollo de aprendizajes y formación profesional en el campo de la gestión escolar.

PALABRAS-CLAVE: Formación de Profesores. Curso de Pedagogía. Gestión educacional y escolar. Pasantía. Práxis.

\section{INTRODUÇÃO}

Um debate permanente marca a trajetória histórica do Curso de Pedagogia no Brasil, envolvido num conflito de identidade em torno da formação do pesquisador da educação, do docente dos anos iniciais, da docência para a educação em diferentes níveis e modalidades e, também, da formação de profissionais para atuação na gestão educacional.

Há consenso de que o foco fundamental do Curso de Pedagogia, sua base, é a docência. Também é possível afirmar que, seja pela formação pedagógica que propicia, seja pela tradição, o curso assumiu formalmente, frente às demais licenciaturas, a responsabilidade pela formação de diretores e coordenadores pedagógicos, formação esta que possui uma especificidade.

$\mathrm{Na}$ perspectiva de uma formação profissional pautada na superação de problemas históricos - a separação teoria e prática, o distanciamento entre universidade e escola, a desarticulação entre disciplinas de conhecimento específico e pedagógico, a fraca consolidação de identidades profissionais -, reconhece-se o estágio como momento formativo por excelência, uma atividade de conhecimento e compreensão das finalidades que compõem o processo de formação docente, “instrumentalizadora da práxis educacional (...) de transformação da realidade existente" (PIMENTA, 1995, p. 122). 


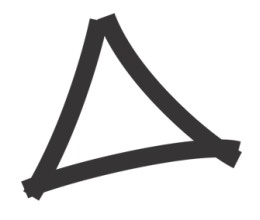

\section{Revista Triângulo}

O objetivo do presente trabalho, então, é discutir o papel do estágio na formação das equipes de gestão no âmbito do Curso de Pedagogia na Universidade Estadual de Ponta Grossa (UEPG), problematizando o modo pelo qual situações didáticas podem mediar as relações teórico-práticas, o estabelecimento de sínteses, o desenvolvimento de aprendizagens e formação profissional no campo da gestão escolar.

\section{A FORMAÇÃo EM GESTÃo EDUCACIONAL NO CURSO DE PEDAGOGIA} DA UEPG

O Curso de Pedagogia, objeto de discussão no presente trabalho, iniciou suas atividades em 1962, voltado à formação de professores para atuação nos cursos de magistério de segundo grau. Sua organização curricular envolvia, basicamente, disciplinas dos fundamentos da educação (Filosofia, Sociologia, Psicologia, História), Matemática e Estatística, Biologia e Estrutura e Funcionamento do Ensino, dentre outras. (PAPI, 2005).

O debate que decorria no país em torno de sua identidade fez com que dez anos depois, em decorrência da lei 5540/68, a instituição o reestruturasse acrescentando, além da formação para o magistério de 20 grau, as habilitações em supervisão escolar, administração escolar e orientação educacional, conforme opção do acadêmico. Este currículo ficou vigente até 1989 e contribuiu para uma forte identificação, na instituição, entre o Curso de Pedagogia e a formação dos então chamados "especialistas da educação".

O debate crítico que passou a ser estabelecido no país a partir da abertura política dos anos 80 envolveu também o Curso de Pedagogia. Além de sua problemática identidade, refletida em organizações curriculares fragmentadas pela formação em habilitações, críticas contundentes apontavam a atuação racionalista, cientificista e conservadora dos "especialistas" os quais atuavam na administração das escolas operando uma divisão do trabalho que tolhia a autonomia política e pedagógica dos professores e contribuía para o alinhamento dos fins educativos aos interesses do capital (PARO, 2010).

A forte crítica à atuação de diretores, supervisores e orientadores educacionais, a defesa da docência como base da formação do pedagogo, as críticas estabelecidas ao Curso de Pedagogia pela problemática relação teórico-prática com as escolas e a realidade educativa e as novas normas de organização de curso adotas pela IES desde 1989 contribuíram para 


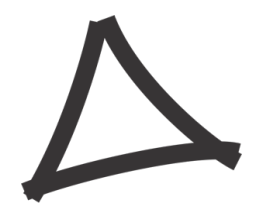

\section{Revista Triângulo}

que, em 1990, ele se reformulasse para formar, central e unicamente, o docente. (SANTOS, 1999).

Além de um corpo comum de disciplinas, o acadêmico faria a opção por uma habilitação docente no campo da docência: Magistério das Matérias Pedagógicas do 2o grau, Magistério das Séries Iniciais de 1o. Grau, Magistério das Classes de Alfabetização e Magistério para a Pré-Escola, ficando extintas as habilitações do campo da gestão escolar (diretor, supervisor, orientador). Um elemento a ser destacado na reformulação foi a introdução, no currículo do Curso, da Disciplina "Práxis Educativa". No esforço de superar as críticas de separação entre as disciplinas (fundamentos da educação, metodologia de ensino e estágio), de dissociação entre a universidade e a realidade educativa e de fragilidade teórica dos estudantes diante das problemáticas que emergiam do trabalho educativo, introduziu-se nas duas primeiras séries do Curso a disciplina de Práxis que objetivou articular, por meio de uma reflexão crítica e do confronto persistente entre teoria e prática, o conjuntos de elementos e realidades formativas: disciplinas da série, disciplinas do Curso, universidade e escola, realidade educativa e formação inicial (SANTOS, 1999).

No que tange à formação em gestão, dois anos depois de sua extinção e por pressão de acadêmicos e redes de ensino, as habilitações em administração escolar, supervisão escolar e orientação educacional são reinseridas no currículo junto das demais existentes.

A persistência de dificuldades formativas (apontadas por processos avaliativos e associadas à carga-horária insuficiente diante da quantidade de demandas) motivou novas alterações curriculares em 1996: buscando reafirmar a identidade em torno da formação do professor, o Curso de Pedagogia assumiu-se como formador de professores para o magistério das séries iniciais do 10 grau e as matérias pedagógicas do 20 grau. Todas as demais habilitações existentes, inclusive as relativas à formação das equipes gestão educacional, foram cursadas após a graduação como complementação ou pós-graduação.

A oferta, pela própria Instituição, do Curso Normal Superior para também formar professores das séries iniciais, fez com que a formação no curso de pedagogia passasse a ser questionada pelos alunos, dada a duplicidade (por eles entendida como similaridade) dos cursos. Em 2000, diante da pressão, procedeu-se nova alteração e a formação em gestão educacional da educação voltou para corpo curricular, agora integrada em torno de uma só 


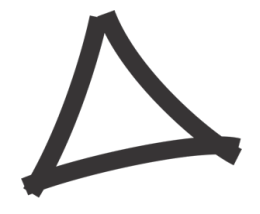

\section{Revista Triângulo}

disciplina ofertada na última série: Fundamentos Teórico-Metodológicos de Supervisão Escolar, Administração Escolar e Orientação Educacional, além do estágio em tal área.

A trajetória tratada torna clara a identificação do Curso, para além da formação de docentes, com a formação das equipes de gestão educacional e, ao mesmo tempo, a crise identitária vivida. A reintrodução do estudo sobre o trabalho das equipes de gestão na última série certamente recolocou tal problemática, pois a junção das três disciplinas anteriormente ofertadas em separado (Pressupostos de Administração Escolar, Pressupostos de Orientação Educacional e Pressupostos de Supervisão Escolar) numa única disciplina voltada a formar o gestor, não garantiu, por si só, a superação do caráter fragmentário na formação do professor x gestor e da própria identidade deste gestor nos papeis de supervisor, orientador e diretor. Infere-se que o esforço para dar aos educadores uma formação com caráter de totalidade continuou a confrontar-se com dificuldades históricas, em especial a fragmentação.

Um longo período de debates e novas diretrizes legais culminou com a reformulação de 2006. Nesta, a inserção das disciplinas de Didática e Gestão Educacional desde a $1^{a}$ série ao lado dos Fundamentos da Educação e demais campos de conhecimento, representou um avanço efetivo em direção a uma maior organicidade na proposta curricular, articulando já no início da formação as identidades de pesquisador, docente da educação infantil, dos anos iniciais do ensino fundamental e das disciplinas pedagógicas no ensino médio (magistério) e gestor. Também podem ser identificados ganhos na busca pela construção de relações teórico-práticas via ampliação do campo da prática educativa ao longo dos 4 anos do Curso na forma de seminários que envolveram também as áreas de seminário das disciplinas pedagógicas do ensino médio e de gestão educacional, constituindo um eixo investigativo cuja finalização se deu pela elaboração de trabalho do Trabalho de Conclusão de curso (com a inserção deste no currículo).

Processos de avaliação institucional levaram o Colegiado de Curso a propor, em 2012, a última reformulação curricular, cuja implantação ainda está em processo. Dentre as alterações feitas é possível destacar maior ênfase às metodologias de ensino, extinção da formação para o magistério de nível médio e desdobramento dos estágios, permitindo inserir, de forma separada, estágios na docência da educação infantil e anos iniciais e na gestão em escolas de educação infantil ou de anos iniciais e em escolas de anos finais do ensino fundamental e/ou médio. 


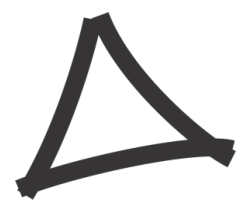

\section{Revista Triângulo}

No que tange à Gestão, o Curso de Pedagogia da UEPG tem, assim, sua formação estruturada, de forma mais específica, nas seguintes disciplinas:

$1^{\mathrm{o}}$ ano - Gestão Educacional I

$2^{\circ}$ ano - Gestão Educacional II e Política Educacional

$3^{\circ}$ ano - Estágio Curricular Supervisionado em Gestão Educacional I, a ser realizado

na Educação Infantil ou anos iniciais do Ensino Fundamental

$4^{\mathrm{o}}$ ano - Estágio Curricular Supervisionado em Gestão Educacional II, a ser realizado

em escola de anos finais do Ensino Fundamental e Ensino Médio, Seminário de

Docência e Gestão e, Planejamento e Avaliação.

$\mathrm{Na}$ medida em que, na proposta curricular, a formação em Gestão Educacional se apresenta de forma a articular em seu conjunto de disciplinas e ao lado da formação de docentes e do pesquisador, problematiza-se o papel do estágio no processo de constituição da identidade e dos conhecimentos em tal área. Ao ser implementado no $3^{\circ}$ ano, buscou-se conferir ao estágio em gestão uma configuração crítica e reflexiva, pautada num movimento de problematização-teorização-práticas e produções de sínteses, conforme trataremos a seguir.

\section{O ESTÁGIO EM GESTÃO EDUCACIONAL}

O trabalho docente possui um caráter de permanente construção e exige capacidade analítica, crítica e de decisão propositiva, para além de uma atuação técnico-aplicadora. Considerando a formação de professores a partir desse pressuposto, recai sobre o estágio uma perspectiva de articulação teórico-prática que permita aos estudantes estagiários

[...] desenvolverem postura e habilidades de pesquisador a partir das situações de estágio, elaborando projetos que lhes permitam ao mesmo tempo compreender e problematizar as situações que observam. Esse estágio pressupõe outra abordagem diante do conhecimento, que passe a considera-lo não mais como verdade capaz de explicar toda e qualquer situação observada, o que tem conduzido estagiários a dizer o que os professores podem fazer. Supõe que se busque novo conhecimento na relação entre as explicações existentes e os dados novos que a realidade impõe e que são percebidos na postura investigativa. (PIMENTA; LIMA, 2012, p. 46).

As dificuldades históricas enfrentadas na formação de professores e no Curso de Pedagogia, em especial no que tange à uma formação com caráter de organicidade e 


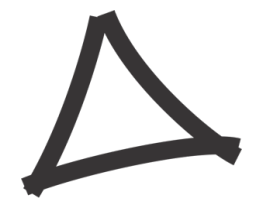

\section{Revista Triângulo}

totalidade, superando o tradicional isolamento entre disciplinas e áreas, teoria e prática, universidade e escola, formação de professores e de profissionais da gestão escolar (SANTOS, 1999), impulsionou para que se organizasse o Estágio em Gestão Educacional numa proposta de caráter crítico e reflexivo.

A mobilização para o sentido pedagógico do estágio se fez pelo estudo de seu papel no processo de desenvolvimento profissional dos estudantes, sensibilizando-os para o esforço teórico-prático implicado. Formulada uma concepção de estágio com os estudantes, estes organizaram-se em duplas e trios e definiram escolas para o início dos trabalhos.

Os estágios tiveram início com a inserção em campo. O conhecimento da realidade condição para os decorrentes planejamento e intervenção - teve a finalidade de viabilizar a construção de diagnósticos que apontassem, em seguida, demandas para a intervenção dos estudantes. A construção de diagnóstico foi organizada na perspectiva da problematização, visando a superação de processos técnicos identificados em anos anteriores, em que a definição de temáticas de estágio era feita de modo relativamente artificial, o que gerava um distanciamento das questões pedagógicas centrais. O risco de uma aproximação técnica e artificial também é apontado por Pimenta e Lima (2012, p. 36) quando dizem que:

O estágio, nessa perspectiva, reduz-se a observar os professores em aula e imitar esses modelos, sem proceder a uma análise crítica fundamental teoricamente e legitimada na realidade social em que o ensino se processa.

Assim, a observação se limita à sala de aula, sem análise do contexto escolar, e espera-se do estagiário a elaboração e execução de "aulas-modelo.

Tomando a realidade como ponto de partida da articulação teórico-prática a ser construída no decorrer do ano letivo, buscou-se desencadear o trabalho dos estudantes numa perspectiva de problematização. Destaca-se que esta problematização foi feita em torno de temática única para todos os grupos da mesma classe, considerando problemáticas centrais já levantadas por eles, no ano anterior, na disciplina de Prática Educativa ${ }^{1}$.

A perspectiva problematizadora associa-se ao olhar intencional e interessado face à realidade escolar, articulado sob os movimentos de objetivação, desnudamento,

\footnotetext{
${ }^{1}$ Nos 10 e 20 anos, esta disciplina articula a aproximação dos alunos com a realidade, as primeiras problematizações e sínteses teórico-práticas a partir da realização de observações e coleta de dados em escolas, contribuição das disciplinas curriculares e da realização de seminários.
} 


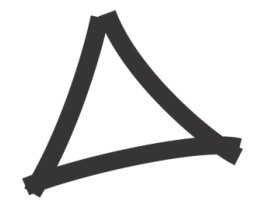

\section{Revista Triângulo}

desnaturalização, questionamento, evidenciamento de contradições, construção explicativa, inferência, compreensão. Toma o aluno como sujeito na construção de seu conhecimento e na transformação da realidade historicamente situada. Segundo Bordenave citado por Freitas (2012, p. 408), a problematização

[...] reconhece a educação como um fenômeno em determinada realidade (física, psicológica e social) entendida como problema também a ser resolvido ou melhorado. A educação, portanto, é o processo de transformação da pessoa, que, por sua vez, empenha-se na transformação da realidade. O aluno, juntamente com seus colegas, é o sujeito de sua aprendizagem.

Em classe, na universidade, os grupos discutiram os elementos trazidos a partir das observações, os dados nos campos de estágio, os referenciais teóricos relativos à temática/problemática e sínteses foram sendo produzidas.

O processo reflexivo também foi buscado pela adoção de narrativas em diários de bordo. De acordo com Amaral, Moreira e Ribeiro (1996, p. 105), o processo de escrever sobre nossa prática pedagógica aguça a sensibilidade para os fatos, permite uma observação mais profunda, viabiliza o diálogo consigo e com a realidade e contribui para a construção de inferências. Há que se ter o cuidado, contudo, para que a escrita "não simplifique demasiadamente aquilo que é complexo". Em cadernos, os alunos estagiários foram estimulados a registrar o que viam, a estabelecer perguntas sobre os fatos e a organizar possíveis elementos explicativos. Este movimento também viabilizou a problematização do próprio professor junto das equipes de estágio na perspectiva da construção de saberes pelos alunos.

A construção do projeto de estágio, que teve início com a entrada em campo, mas transversalizou as etapas de elaboração de diagnóstico e planejamento, expressando a intencionalidade do estudante em relação a seu processo de aprendizagem profissional, além de configurar-se como importante momento de elaboração de quadros referenciais enquanto recursos analíticos:

o papel das teorias é iluminar e oferecer instrumentos e esquemas para a análise e investigação que permitam questionar as práticas institucionalizadas e as ações dos sujeitos e, ao mesmo tempo, colocar elas próprias em questionamento, uma vez que as teorias são explicações sempre provisórias da realidade. (PIMENTA; LIMA, 2012, p. 43). 


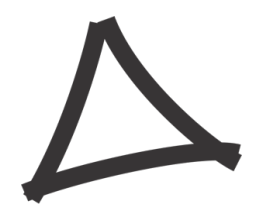

\section{Revista Triângulo}

A partir dos projetos de estágio as equipes estruturaram também os planos de ação. Na lógica buscada, o trabalho em campo intencionava superar a concepção aplicacionista e técnica de prática de ensino como reprodução de esquemas existentes ou de experimentação de habilidades técnicas. Buscou-se que os alunos problematizassem seu próprio estágio (frente ao real que se descortinava), apontando intencionalidades e objetivos diante da necessidade de inserir-se neste real, de intervir.

Os dados coletados por meio de questionário no momento de diagnóstico foram organizados, categorizados e estudados em busca de compreensões. A objetivação da problemática evidenciou os contextos global, local e suas inter-relações, questões sistêmicas e particularidades das instituições. Mais do que um estudo de caso ou resolução de situações problema, o estágio é prática pedagógica e confronta-se com suas potencialidades, contradições e limitações diante da realidade que se pretende ver superada, o que dá relevância política ao ato de planejamento como processo intencional. Assim, pretendia-se que os planos de ação resultassem do movimento analítico entre ideal, real e possível a fim de que, diante das alternativas de enfrentamento identificadas, selecionassem-se as que fossem coerentes não apenas com o contexto escolar, mas com as condições do estágio.

$\mathrm{Na}$ perspectiva de construção teórico-prática, o estágio busca que o futuro professor experiencie diferentes contextos pedagógicos e envolva-se com as situações do real e da dinâmica cotidiana escolar por meio das intervenções, conforme aponta Berbel (1998, p. 40)

[...] o confronto é com o real acontecendo, em situação prática, dinâmica, interativa com os componentes do meio; onde o pensado se transforma em prática; onde se aprende a adequar a relação teoria-prática; onde a dialética da ação-reflexão-ação é possibilitada e exercitada.

A intervenção em campo de estágio é um momento do processo formativo que envolve desenvolvimento de habilidades, troca/partilha de conhecimento e que, ao mesmo tempo, gera tensões diante das contradições que a concretude do real provoca junto aos conhecimentos (teóricos e práticos) do estudante estagiário, tornando fundamentais os processos de mediação.

A mediação docente na reflexão sobre a intervenção na prática escolar se sustentou no acompanhamento em campo do supervisor técnico da instituição escolar e do professor de estágio. A partir das observações, buscou-se contribuir para a construção de saberes e sínteses 


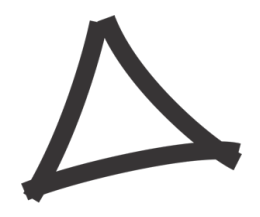

\section{Revista Triângulo}

retomando esses movimentos novamente, bem como, autoavaliação e problematização. Estes processos ocorreram no próprio campo de estágio (quando havia recursos de tempo e espaço disponíveis) e/ou no espaço da universidade e envolveram momentos individuais com as equipes de estágio e coletivos da classe de estágio como um todo para identificação de aproximações, problematizações, construção de compreensões possíveis e inferências. Destaca-se aí o papel dos encontros semanais em sala como fundamentais para o estudo de referenciais capazes de sustentar a busca de compreensão das práticas experienciadas, seus resultados e aspectos limitadores.

Na perspectiva de construção de conhecimento em Gestão Educacional, encaminhouse junto aos alunos uma produção escrita na forma de artigo. O objetivo foi o de sistematizar e discutir as categorias inicialmente elencadas no diagnóstico revisitando dados da realidade, primeiras hipóteses e explicações, fundamentos teóricos, análises e compreensões construídas no estágio em termos de seu conteúdo - temática da gestão escolar tratada no estágio - e forma - o estágio como processo de formação profissional. Diários de bordo, projetos de estágio, dados empíricos e registros de avaliação foram revisitados pelos estudantes numa perspectiva de rever os saberes e sínteses construídas no processo de estágio. A mediação do professor durante o processo de escrita possibilitou a elaboração de novas sínteses e reflexões no percurso formativo.

\section{CONSIDERAÇÕES FINAIS}

Formar professores é tarefa complexa. A intencionalidade crítica no que tange ao papel da educação, do trabalho docente e da gestão das escolas pressupõe um projeto que ultrapasse a junção de disciplinas e atividades, sendo capaz de preparar para a compreensão do complexo - enquanto multideterminado e multifacetado - e do contraditório e para sua transformação qualitativa.

A trajetória do Curso de Pedagogia na UEPG revela a busca dessa perspectiva. As várias reformulações pelas quais o Curso passou demonstram a clareza quanto aos problemas a serem enfrentados e a contínua reflexão quanto às formas de fazê-lo; importantes iniciativas decorreram daí. 


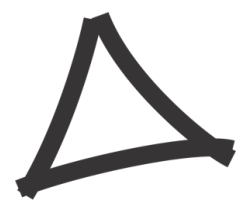

\section{Revista Triângulo}

Uma das questões com que o Curso se debateu ao longo dos anos foi a formação das equipes de gestão educacional e escolar. Destaca-se nesta questão a fragmentação dos próprios profissionais, divididos entre diretores, supervisores e orientadores e a fragmentação em relação ao docente cuja formação e identidade deveriam fundamentar o trabalho de coordenação [administrativa e pedagógica] de escolas.

Posicionar a gestão ao lado da formação docente no decorrer do Curso foi uma medida importante adotada a partir da reformulação de 2006, mas, por si só, insuficiente do ponto de vista da questão da conquista de uma formação política, densa e articulada quanto ao conjunto de conhecimentos e práticas pedagógicas contempladas.

De acordo com Cavagnari e Santos (2003, p. 124), o processo analítico-reflexivo não é simples ou imediato; por tratar-se de "um movimento de pensamento complexo, rigoroso, sistemático, inserido numa totalidade [...] envolve um permanente compartilhar entre os sujeitos, trazendo à tona temas problemáticos que o grupo precisa compreender num movimento prático-teórico". É neste movimento que situamos o papel do estágio na formação profissional.

Ao problematizar a formação de diretores e coordenadores pedagógicos em termos da consolidação de tais identidades e da construção dos saberes a elas correspondentes, apontamos para o estágio como espaço de sínteses e de construção de conhecimento no campo da Gestão Educacional, com a correspondente configuração de trabalho na direção intencionada.

Destaque-se, por fim, que o trabalho com o estágio nesta perspectiva torna imprescindível o processo formativo-reflexivo do próprio formador, vivenciando momentos de meta-reflexão a partir do enfrentamento das situações e relações estabelecidas, neste processo, com os estudantes estagiários.

\section{REFERÊNCIAS}

AMARAL, M. J. MOREIRA, M. A. RIBEIRO, D. O papel do supervisor no desenvolvimento profissional do professor reflexivo: estratégias de supervisão. In: ALARCÃO, I. (Org.). Formação reflexiva de professores: estratégias de supervisão. Porto: Porto Editora, 1996.

BERBEL, N. A. N. (Org.). Metodologia da problematização. Londrina, Eduel, 1998. 


\section{Revista Triângulo}

FREITAS, R. A. M. da M. Ensino por problemas: uma abordagem para o desenvolvimento do aluno. Educação e Pesquisa, São Paulo, v. 38, n. 2, p. 403-418, abr./jun. 2012.

CAVAGNARI, L. B. SANTOS, S.A síntese elaborada de curso como metodologia reflexiva de formação: a experiência do curso normal superior com mídias interativas. Olhar de professor, Ponta Grossa, n. 6, v. 1, p. 119-134, 2003.

PAPI, S. O. G. P. Professores: formação e profissionalização. São Paulo: Junqueira e Marin, 2005.

PIMENTA, S. G. O estágio na formação de professores: unidade teoria e prática? 2. ed. São Paulo: Cortez, 1995.

PIMENTA, S. G.; LIMA, M. S. L. Estágio e docência. 7.ed. São Paulo: Cortez, 2012.

PARO, V. H. Administração escolar: introdução crítica. 16. ed. São Paulo: Cortez, 2010.

SANTOS, S. O curso de Pedagogia da Universidade Estadual de Ponta Grossa e os nexos entre teoria e prática: uma análise necessária. Olhar de Professor, Ponta Grossa, v. 2, n. 2,p. 81-93, jan./dez.1999. 